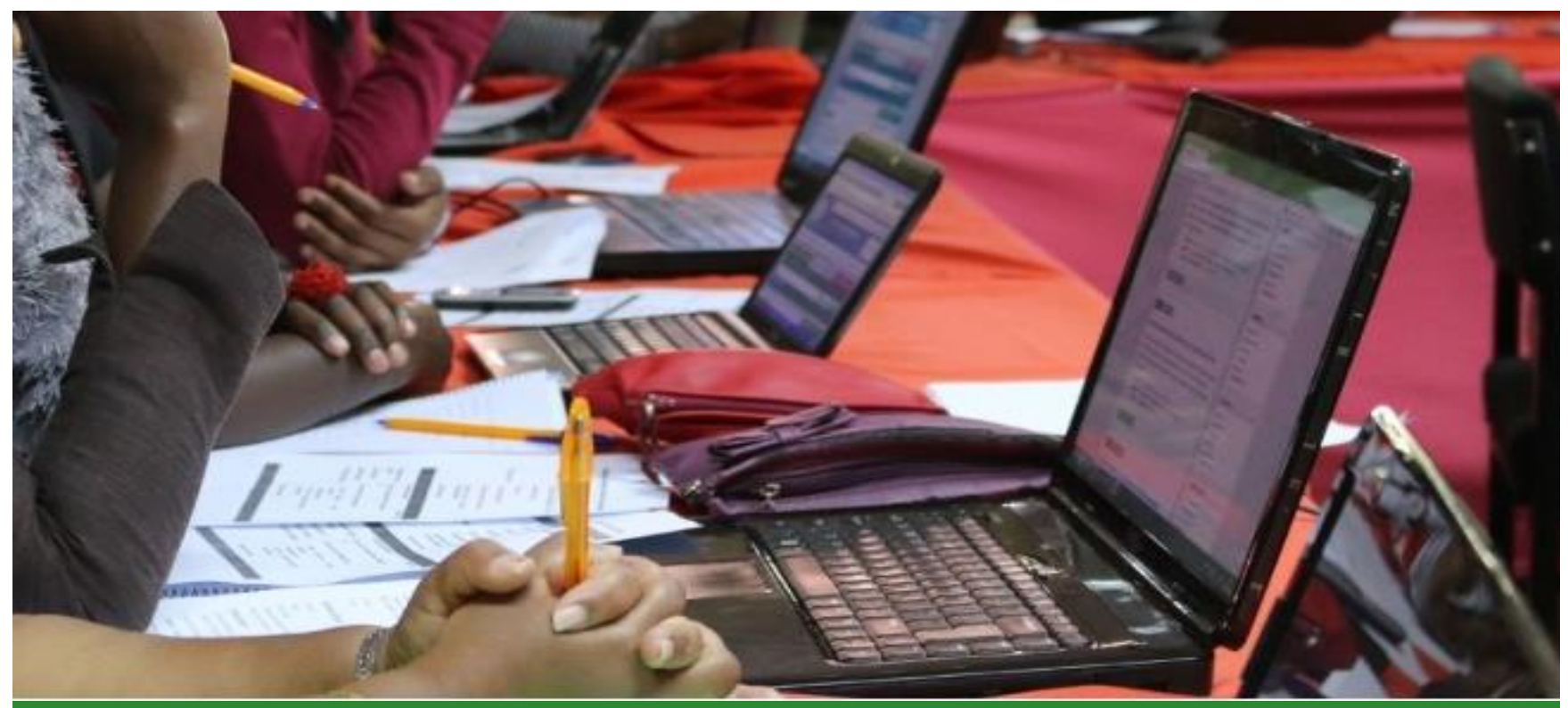

\title{
E-resources for agricultural research capacity building in African universities
}

\author{
David Onyango, Martin Parr, Roger Day and Njogu Festus \\ Muitherero
}

\section{Summary}

The Regional Universities Forum for Capacity Building in Agriculture (RUFORUM) and CABI are collaborating to strengthen tertiary agricultural education in Africa through provision of privileged, costfree access to two of CABl's valuable scientific information resources, CAB Abstracts database and $\mathrm{CABI}$ Compendia, to all the universities that make up the RUFORUM consortium.

Between September 2013 and December 2015 usage of the e-resources generally grew and peaked immediately following awareness creation campaigns and training. Low usage in some of the universities was attributed to limited promotion of the e-resources, lack of skills needed to use them and poor information technology infrastructure to support their use.

Where used, the CABI e-resources were mostly utilized in writing proposals and articles and for consultancies and professional research. They reduced the time spent searching for content online and led to better quality, scope and volume of research output.

To realize the benefits attributed to the CABI e-resources, systematic awareness creation and regular training of both librarians and e-resource users are essential. Awareness creation, which should be continuous and should target top university management, librarians, lecturers and students, should be conducted using seminars, workshops, university websites, social media, flyers, posters and other channels. Training of librarians should be regular and geared towards enhancing their capacity for proficiency in the use of existing and new e-resources. A system is also required to track, analyse and report on e-resource usage to understand the trends, which will help in developing the strategies and interventions to ensure optimal utilization of the e-resources. 


\section{Key highlights}

- Awareness creation and training on the $\mathrm{CABI}$ e-resources were crucial factors in increasing their usage

- $\mathrm{CAB}$ Abstracts had the highest overall usage among the CABI databases available in the universities, probably owing to its wide subject coverage

- The CABI e-resources were highly regarded for their scholarly value, with more than three-quarters of the users indicating that they would likely recommend them to colleagues

- The CABI e-resources were used to best effect in writing proposals and articles and in consultancies and professional research

- When used, the CABI e-resources were reported to enhance information access and retrieval, increase and improve research output, improve referencing skills and reduce the time taken to access online content

- Usage of $C A B I$ e-resources was extremely low compared with the other e-resources such as Google, Google Scholar, AGORA and HINARI

- Inadequate awareness of the CABI e-resources, poor user skills, insufficient accessibility to computers, and infrastructural limitations associated with information technology were considered the main factors responsible for the low usage of the e-resources

\section{Contexts}

Africa relies on agriculture for its economic growth and that sector contributes $65 \%$ of the continent's gross domestic product. However, agricultural productivity lags behind that of the other continents, one reason being that Africa is deficient in the skills required for agricultural development. To serve their role as key contributors to the development of agriculture through the research they undertake and the skills they build, African universities need up-to-date information, and particularly e-resources, considering that information is being generated and delivered at unprecedented speeds. Current information is an essential prerequisite for quality research, to find out what has been done, to find new ways of doing things and for networking of professionals, among other things. E-resources today are at the heart of academic knowledge management, and research has shown that their proper utilization positively impacts scholarly work. But access to such information is limited in Africa owing mainly to costs of subscription, but also in some cases poor technical infrastructure.

\section{What we did}

In 2012, the Regional Universities Forum for Capacity Building in Agriculture (RUFORUM) and CABI entered into a strategic collaboration to strengthen tertiary agricultural education in Africa through provision of privileged, cost-free access to two of CABI's valuable scientific information resources, CABI Abstracts database and CABI Compendia, to all the universities that make up the RUFORUM consortium. RUFORUM is working to help African universities build capacity and foster innovations that respond to the demands of smallholder farmers. Its membership at the initiation of the collaboration stood at 32 universities from eastern, central and southern Africa. The 14 universities from across the continent that joined the consortium in 2014 do not yet have privileged access to the CABI e-resources.

CAB Abstracts is a comprehensive database of over 10 million records with more than 360,000 abstracts added annually. It covers applied economics, environment, food science and nutrition, veterinary sciences and agriculture. CABI Compendia is an encyclopaedic reference with multimedia tools focusing on animal health, aquaculture, crop protection, forestry and invasive species. The use of these e-resources has potential to bring about innovative research outputs responsive to the demands of smallholder farmers and to strengthen tertiary agricultural education systems.

Awareness campaigns promoting the e-resources among the universities' communities were conducted by CABI every month using social media platforms such as Facebook and Twitter, university email lists and university newsletters. Training-of-trainers sessions, along with workshops, 
webinars and self-directed online modules, were used to build capacity in the use of the e-resources. In 2014, 12 training sessions were conducted in 10 universities for 267 librarians, lecturers, researchers and students, along with two webinars. One training workshop was held in 2015.

Usage of the e-resources was tracked with Google Analytics and COUNTER 4 - an international, extendible code that allows the usage of online information products and services to be measured in a credible, consistent and compatible way. A cross-section of users were interviewed and a case study was undertaken at the College of Agriculture and Veterinary Sciences (CAVS) of the University of Nairobi in 2014-2015 to establish how the e-resources were being repurposed and their impact on research.

Over September 2013 to December 2015, the period covered by this brief, usage of the e-resources generally grew, and peaked in the time immediately after awareness creation campaigns and training. Low usage in some of the universities was attributed to limited promotion of the e-resources, lack of skills needed to use them and poor information technology infrastructure to support their use.

\section{Findings}

In large part, the tracking mechanisms showed an increase in the use of the CABI e-resources over time, growing from a total of 4,894 interactions during the last four months of 2013, when the privileged access collaboration was initiated, to 120,030 in 2015 (Figures 1 and 2). The highest level of usage of 45,000 interactions was observed in July 2015 (Figure 2).

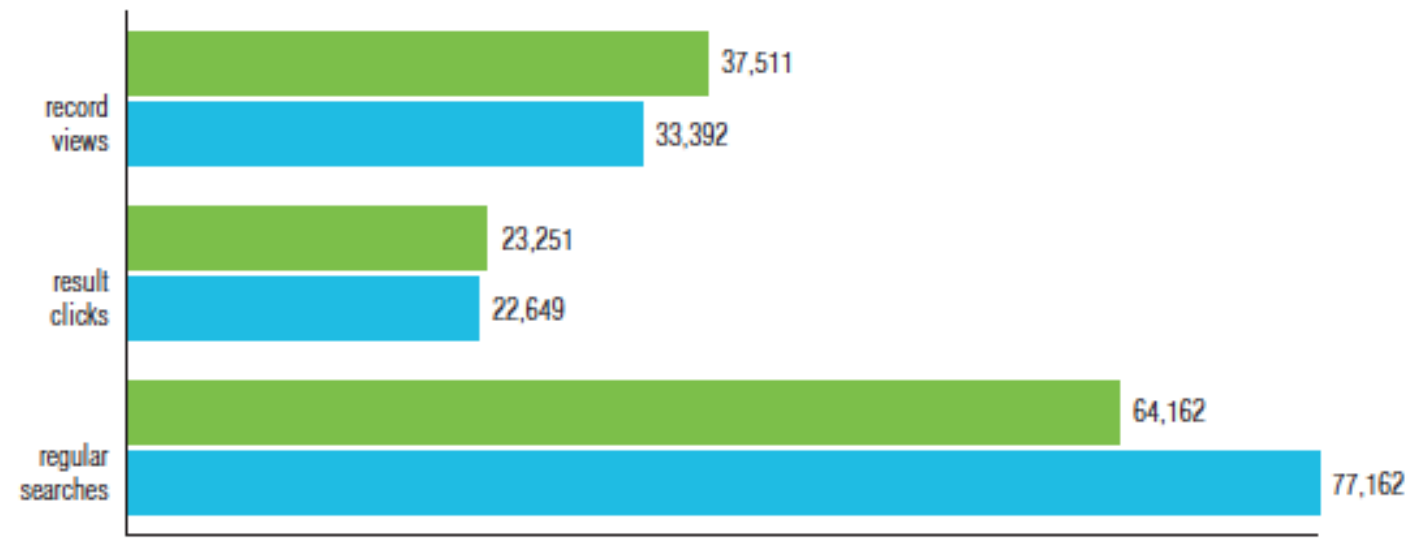

Figure 1. CABI e-resources usage in 2014 and 2015.

Fluctuations were observed in the trend of usage of the e-resources associated with their promotion activities and the universities' academic cycles. Awareness campaigns and training on the eresources, for example during February, May, September and October 2014, generated increases in their utilization (see Figure 2). Usage also went up at the end of the semester, which is when the universities administer examinations, but dipped during the university recess periods. 


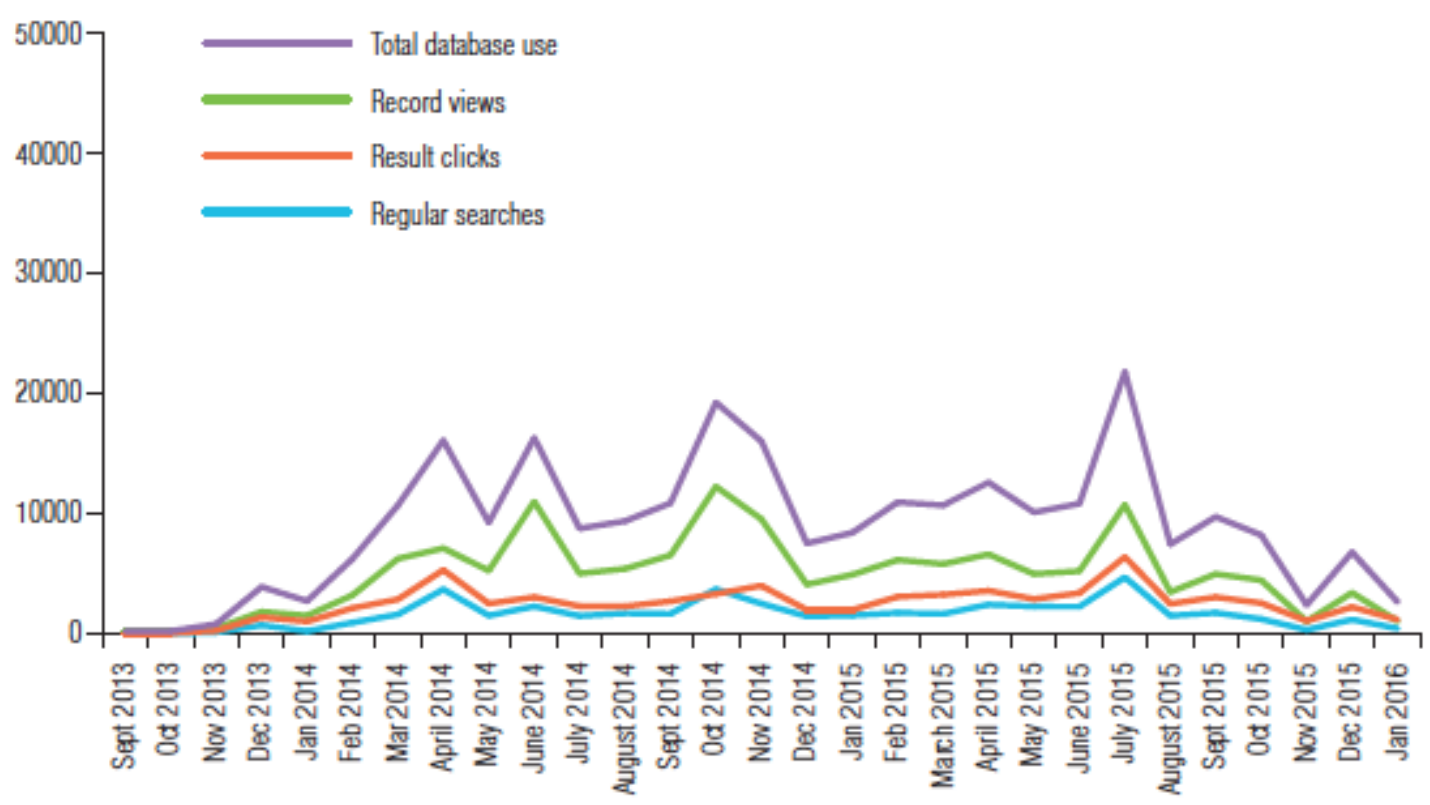

Figure 2. CABI e-resources use trends by RUFORUM consortium universities during 20142015.

There was a wide variation in usage of the e-resources among the individual universities. The University of Nairobi was ranked highest in database visits and downloads in both 2014 and 2015, a period over which its total interactions grew from 11,878 to 96,306 . In 2015 , the University of Nairobi had more than three times the usage of next-ranked Jomo Kenyatta University (Figure 3). The Catholic University of Mozambique, the Catholic University of Bukavu, Kyambogo University and the University of Juba recorded no usage in both 2014 and 2015.

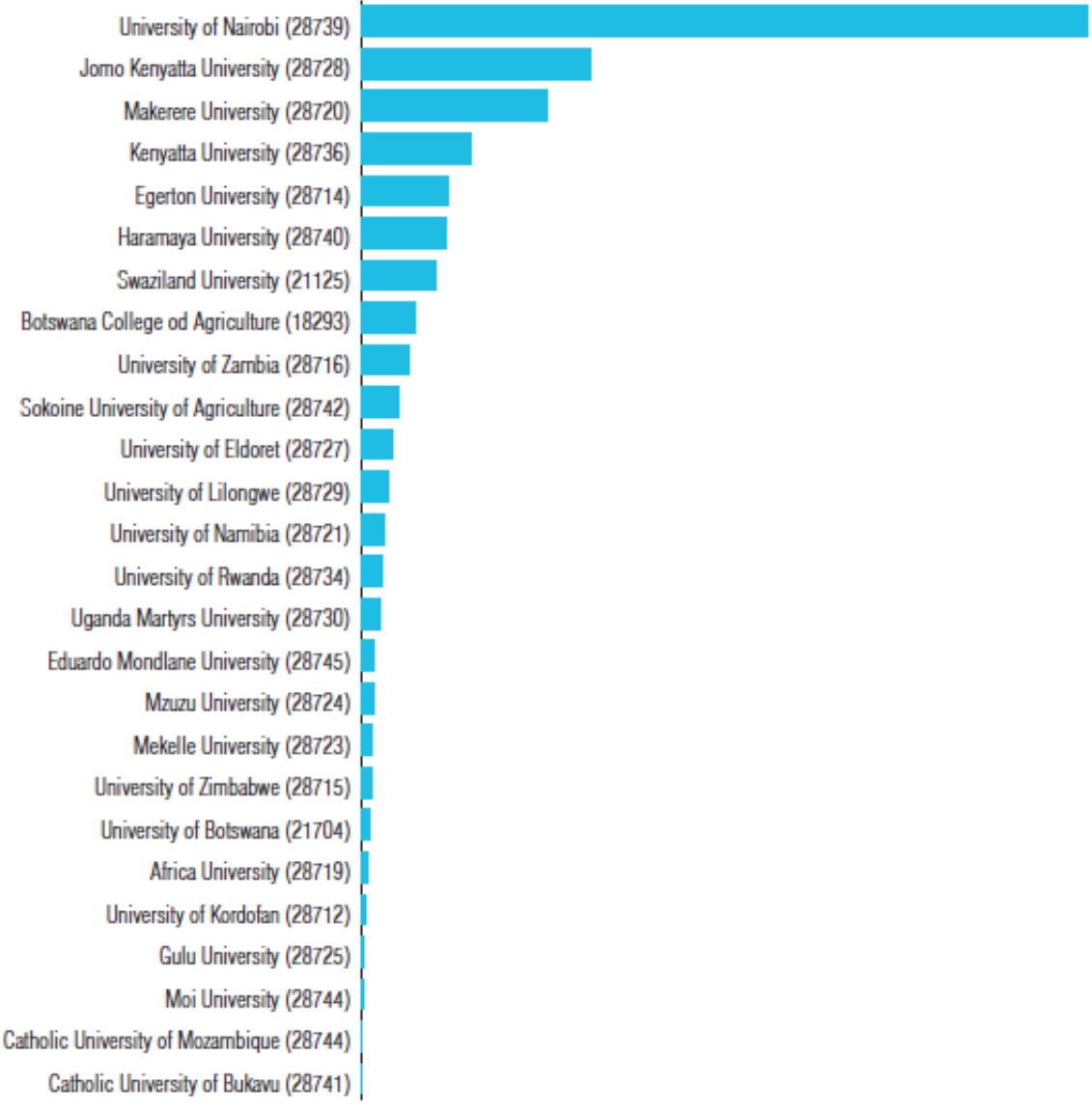

Figure 3. CABI e-resources usage by individual RUFORUM universities in 2015.

E-resources for agricultural research capacity building in African universities 
Both online usage tracking and the CAVS study found CAB Abstracts to have the highest overall usage among the databases available, probably owing to its wide subject coverage, as opposed to the $\mathrm{CABI}$ Compendia, which are subject specific. At CAVS, CAB Abstracts was utilized by $73 \%$ of the users.

The CABI e-resources were regarded by the librarians and university faculty and students who used them to have a high scholarly value. The CAVS study found that $91 \%$ of the teaching staff and undergraduate students, and $85 \%$ of the postgraduate students interviewed considered them relevant or highly relevant. Also high were the scores for the likelihood of recommending them, where $100 \%$ of the librarians, $93 \%$ of the teaching staff, $79 \%$ of the undergraduate students and $70 \%$ of the postgraduate students said they would definitely or likely recommend them to their colleagues. Other factors that fostered their use were their ease of access and use, relevance of their content, userfriendliness of the interface, credibility, and the comprehensiveness in their coverage of key agricultural journals. The comments from the users demonstrate this:

The user friendliness of the CABI e-resources will make my job easier than ever before. I am no longer required to be at the campus to do my searches. This has saved time and of course money for travelling back and from home

- Shaabani Mshamu, lecturer, Sokoine university of Agriculture, Tanzania.

The literature contained in the databases was comprehensive, having been [put together] by specialists in various fields. This enabled me to save on time that would have otherwise been spent looking for the same information in several other databases

- Oliver Otieno, MSc student in crop protection, CAVS.

Our users now have a broader access to new knowledge as a result of access to the CABI eresources. The world will be at their fingertips and the institution library can now produce relevant content for research

- J. Magdalena, senior librarian, University of Namibia.

These resources are usually my first stop when I want to get a world perspective of where diseases and pests have been spotted; maps are particularly useful for this purpose. I also advise my students to start with CAB Abstracts and Compendia. Exposing students to the right information develops them into professionals who can generate real solutions for challenges all over the world

- Dr Douglas Miano, plant virologist and lecturer, CAVS.

According to the CAVS study, the CABI e-resources were mostly used in writing proposals and articles, which was the case for $42 \%$ of the users, followed by consultancies and professional research, with $39 \%$ of the users, assignments, with $25 \%$ of the users, and preparation of projects and for university examinations, with $19 \%$ of the users. By widening the scope and increasing the volume of relevant search results, improving information access and retrieval, and reducing the time spent searching for content online, the CABI e-resources led to better quality of research output among their users. Information access and retrieval were enhanced for $50 \%$ of the respondents in the CAVS study, research output was increased for $34 \%$, referencing skills were improved for $32 \%$, and the time taken to access online content was reduced for $31 \%$. For $24 \%$ of the users, the e-resources improved the quality, scope and volume of research output. These facts were also expressed in the comments of the study respondents:

These resources have a search process that is efficient which saves time. I personally believe that these databases have improved the quality of research that I am doing. As I pursue my MSc, I will need to look for background information and do literature review

- Aidah Mugambi, MSc student in agricultural resource management, CAVS.

Users of these $C A B I$ e-resources have an advantage because it provides information on all diseases, not only those found at the students' environment, but also those that may be found 
elsewhere. They enhance the diagnostic skills of students, since they will be able to visually see and conceptualise the diseases they are working on, which is very important for diagnosis

\section{- Professor James Muthomi, Department of Plant Science and Crop Protection,} CAVS.

These resources introduce students to scientific writing which is important because usually when students present their work for conferences the first thing organizers ask for is the abstract. ... A person who does not use the CABI databases has lesser access to global literature which can lead to shallow research when one does work already done by others. ... those who have access to literature present very good term papers and theses because they are able to do a critical analysis of their subject. There is a big difference and it affects quality

- Professor Paul Kimani, Department of Plant Science and Crop Protection.

The positive attributes associated with the use of the CABI e-resources notwithstanding, the CAVS study found the usage of the CABI databases to be low compared to other e-resources. In fact, $78 \%$ of the survey participants had not used the e-resources at all, preferring services such as Google and Google Scholar, which were used regularly by $89 \%$ of the respondents, AGORA with $47 \%$ of the users, and HINARI with $32 \%$ of the users, among others. Furthermore, the few people who used the CABI e-resources used them infrequently. Among the CAVS study respondents, $10 \%$ used the resources once a week, $11 \%$ once a month and $6 \%$ once every three to four months. The time expended on the e-resources was limited as well, with $64 \%$ of the users spending one to two hours per session, while $32 \%$ spent less than one hour.

Lack of awareness of the CABI e-resources was the main reason given in the CAVS study for their low use. Altogether, $50 \%$ of the respondents were unfamiliar with the e-resources. Among the lecturers and students, $63 \%$ were unaware of either CAB Abstracts or CABI Compendia, $11 \%$ were aware of only one, and only $24 \%$ were familiar with both. The poor awareness of the e-resources offered by the library was not limited to the CABI products, though, but was widespread, and $68 \%$ of the respondents could name only $1-5$ of the 11 e-resources available through the library.

The low awareness on CAB Abstracts and CABI Compendia among the librarians, students and lecturers at CAVS was attributed to limited promotion within the college. Those who were aware of the resources had learnt about them from library assistants, workshops and exhibitions or websites. Whereas the library used social media for delivering information to users, it did not make use of that channel to create awareness on the $\mathrm{CABI}$ online products. All the librarians believed that the $\mathrm{CABI} e-$ resources had not been adequately promoted.

Significant factors contributing to the low use of the CABI e-resources at CAVS were the poor use skills and unfamiliarity with the e-resources among the librarians and the library users. The librarians were expected to be sufficiently prepared to support library users to obtain maximum benefit from the $\mathrm{CABI}$ e-resources, but most of them were not proficient in the use of the e-resources. None of the librarians considered his or her skills as advanced in using CAB Abstracts and CABI Compendia, $57 \%$ of them rated themselves as moderate and $29 \%$ as poor. Some $14 \%$ the librarians had never used the e-resources. Among the library users, $13 \%$ of the lecturers and $64 \%$ of the students viewed their skills in $\mathrm{CABI}$ e-resources as poor, and only $2 \%$ of the postgraduate students regarded themselves as very good users. $17 \%$ of the respondents considered the lack of knowledge and skills in using the eresources as a key challenge.

That the CAVS community had a low level of competence in the use of the CABI e-resources should not be surprising considering that only $43 \%$ of the librarians had undergone the formal CABI training on the e-resources and that these librarians did not train their colleagues. Although another $14 \%$ of the librarians were trained through a CABI webinar and $29 \%$ by a combination of webinars, on-campus events ran by $\mathrm{CABI}$ staff, and from the $\mathrm{CABI}$ website, that was not adequate to build the skill levels required to support the e-resource users. Among the library users, $59 \%$ of the students and lecturers had been trained on access and use of e-resources, but $88.5 \%$ had not been trained on CABI eresources. Some $76 \%$ of the respondents were not aware of any training on the CABI e-resources. Had the CAVS librarians tracked e-resource use and analysed the statistics, they would have found the gaps and probably taken steps to have them dealt with, but they did not do that. 
Infrastructural shortcomings associated with information technology and inadequate accessibility to computers played a substantial role in the low utilization of the CABI e-resources at CAVS. For example, the library did not make provision for users to connect to the internet. Additionally, the speed of the Internet was slow, and poor internet connection was considered by $66 \%$ of the respondents as the topmost hindrance to access to e-resources in general, and by $43 \%$ to access to the $\mathrm{CABI}$ resources. There were difficulties also with access to passwords for CABI e-resources, a limitation that affected $32 \%$ of the respondents. Access to personal computers was a problem for $22 \%$ of the respondents.

\section{Way forward}

To realize the benefits attributed to the $\mathrm{CABI}$ e-resources, systematic awareness creation and regular training of both the librarians and the e-resource users are essential. Awareness creation, which should be continuous and should target top university management, librarians, lecturers and students, should be conducted using seminars, workshops, university websites, social media, flyers, posters and other channels. A new CABI regional sales manager based in Nairobi from 2016 will be taking on some of these tasks and promoting products across sub-Saharan Africa. This will allow CABI to raise awareness with members of regional networks such as RUFORUM and FARA (Forum for Agricultural Research in Africa) and librarians at meetings, conferences and via email. Training of librarians should be regular and geared towards enhancing their capacity for proficiency in the use of existing and new e-resources. A system is also required to track, analyse and report on e-resource usage to understand the trends, which will help in developing the strategies and interventions to ensure optimal utilization of the e-resources.

A recommendation from the CAVS study that could apply also to other universities is the need to strengthen Wi- Fi signals to allow easy and convenient access to e-resources, given that mostly laptops are used to access the e-resources, and typically that is from outside the library. Also, if university departments take it upon themselves to train their students on the proper use of the eresources that are relevant to their programmes, overreliance on generic search engines, especially Google and Google Scholar will be reduced. In addition, as the CABI e-resources are used to most effect in writing proposals and articles, and in consultancies and professional research, special attention should be directed at promoting them among postgraduate students and lecturers who most require the specialized and focused information that these resources provide.

\section{Further reading}

Muitherero, N.F. 2015. Assessment of agricultural e-resource use and its impact: the case of University of Nairobi. MSc thesis. Nairobi: University of Nairobi.

Owino, D.O. 2014. CABI-RUFORUM collaboration progress report: strengthening tertiary agricultural education in Africa, 8/01/2014.

Owino, D.O. 2015. CABI-RUFORUM 2014 collaboration progress report: strengthening tertiary agricultural education in Africa. 



\section{Acknowledgements}

$\mathrm{CABI}$ is an international intergovernmental organisation, and we gratefully acknowledge the core financial support from our member countries (and lead agencies) including the United Kingdom (Department for International Development), China (Chinese Ministry of Agriculture), Australia (Australian Centre for International Agricultural Research), Canada (Agriculture and Agri-Food Canada), Netherlands (Directorate-General for International Cooperation), and Switzerland (Swiss Agency for Development and Cooperation).

\section{Project donors}

CABI Development Fund supported the case study development

\section{Authors}

David Onyango, CABI

Martin Parr, CABI

Roger Day, CABI

Njogu Festus Muitherero, Kenya Agricultural Information Resource Centre

\section{Editorial team}

Kellen Kebaara (Technical writer)

Dannie Romney, Martin Parr (Editorial Coordinators)

\section{How to cite this paper}

Onyango, D., Muitherero, N.F., Day, R., Parr, M. 2016. E-resources for agricultural research capacity building in African universities. CABI Study Brief 17. DOI http://dx.doi.org/10.1079/CABICOMM-45-118 